\title{
EDITORIAL
}

\section{A prize purpose}

\author{
The Longitude Prize 2014 has stimulated debate over the true purpose of these initiatives \\ and whether the public can rise to the challenge of making such decisions.
}

In 1714, the Parliament of Great Britain passed the Longitude Act, which was aimed at solving one of the most pressing scientific problems of the day - how to accurately determine longitude while at sea. The Longitude Act was passed after several maritime disasters occurred as a result of sailors being unable to accurately determine their position, and it led to the establishment of a Board of Longitude that comprised luminaries such as the Astronomer Royal. The board offered a prize of up to UK£20,000 to anyone who could invent a practical method to determine longitude during a sea voyage, with smaller sums available to provide financial support to those investigating methods that were deemed promising. In a story that was elegantly recounted in the book Longitude by Dava Sobel, John Harrison, who was a carpenter and amateur horologist, had invented a marine chronometer that fulfilled the specific terms of the Longitude Act by 1762 . Indeed, Harrison went on to produce a series of improved chronometers, but although he did eventually receive some money from the board, the award was mired in dispute and mistrust and the main prize remained unclaimed. The importance of Harrison's work - and the intricate beauty of his chronometers - was only really appreciated much later.

However, 300 years on the Longitude Prize has now been rebooted. In May 2014, the UK-based innovation charity Nesta and the Technology Strategy Board formally launched the $£ 10$ million Longitude Prize 2014, which is aimed at solving 'one of the greatest issues of our time'. An 18-member Longitude Committee, chaired by the current Astronomer Royal Martin Rees, was established to oversee the process. During a series of discussions and workshops over the past year, the many avenues that could be explored have been debated, sieved through and eventually whittled down to a shortlist of six.

The issues that made it to the final six are all very different, encompassing a range of areas of science, technology and medicine, but all feature global problems for which a successful solution would bring major benefits to society. The chosen issues are presented under single-word headlines: Flight, Water, Paralysis, Dementia, Food and Antibiotics, but underpinning each headline is a specific challenge. To take just three examples: for
Water, the challenge is "to develop a cheap, environmentally sustainable desalination technology"; for Paralysis, "to invent an affordable and practical solution that gives paralysed people close to the same freedom of movement as everyone else"; and perhaps of greatest interest to microbiologists, for Antibiotics, the challenge is "to develop a cost-effective, accurate, rapid, and easyto-use test for bacterial infections". The launch of the new prize was announced in a special edition of the BBC science programme Horizon, and in an interesting twist, the winning challenge will be selected by a public vote, which runs until 25 June. Once selected, the winning challenge is then open to anyone to solve.

The revival of the Longitude Prize has provoked plenty of debate and critical reaction. Some of the criticism has focused on the format, as it is the public who will choose the specific challenge that is taken forward. It is true that (in the UK at least) there are very few periods in the year during which at least one main television channel isn't showing a Saturday night prime-time dancing, singing or general 'talent' contest in which the public can cast their votes. And indeed, choosing whether one is more interested in curing paralysis or helping to alleviate the burden of antibiotic resistance perhaps does seem a little crass. However, the organizers counter this by pointing out that the public currently have very little say in the allocation of research funding and that an increased involvement, even on a small scale, may reinforce the importance of science not only in solving complex problems but also in our daily lives. Jazzing up the competition with television and radio programmes and a public vote is not lowering the tone of the debate, but is merely presenting it in an accessible way that will be able to compete with all of the distractions of modern life.

Doubt has been expressed over whether any of these problems could actually be solved with $£ 10$ million. Of course, if it leads to a new point of care test for bacterial infection, that would be a fantastic end to the story. However, perhaps the value of this initiative does not really lie in completing the challenge per se but in emphasizing the general public's 'ownership' of government-funded science and promoting science and scientific problems in everyday conversation. The organizers may well be satisfied if they succeed in achieving these goals. 